\title{
Words, numbers, warnings, tips, but still low risk perception
}

\author{
Laura Macchi ${ }^{1}$
}

Received: 20 July 2020 / Accepted: 25 August 2020 / Published online: 5 September 2020

(c) Springer-Verlag GmbH Germany, part of Springer Nature 2020

\begin{abstract}
Psychology of communication must do everything is possible to promote an adequate perception of risk. This is particularly true when it comes to transmitting statistical and probabilistic data to an audience of non-experts, inevitably conditioning their perception of risk. Data are all available, but subjects are able to understand them in the specific meanings proper to a specialized language, only if they are adequately transmitted. And we find these phenomena in the difficulty in representing the trend of, for instance, Covid-19 contagion, based on probability of contagion and mortality. In general, then, when we communicate scientific terms or data we should re-introduce the psychological aspects which characterize communication. The nudging strategies can be considered as a prototype of approach to overcome risky behaviours, which takes into account the cognitive characteristics of the human system. This strategy acts on different levels, using implicit factors, bypassing defensive attitudes and exploiting adaptive inferential processes, without overloading the cognitive system. But from a communicative point of view, nudge, as well as any other type of intervention, is not a general 'recipe. The acceptance of the suggestion, the effectiveness of the nudging implies the congruity with the system that receives it: the "way of reasoning", and its implicit layer has to be taken into account. The right combination of the source, the adopted message and the decisional setting could improve the efficacy of the public policies.
\end{abstract}

Keywords Perception of risk · Communication · Nudging

My research and teaching have developed in strongly related ares, exploring the relationship between language and thought. By adopting a pragmatic approach, thought has been investigated by highlighting the effect of task formulation on probabilistic reasoning, decision making and problem solving.

Laura Macchi

laura.macchi@unimib.it

1 Department of Psychology, University of Milano-Bicocca, Milan, Italy 
Conditioned by this approach as I am, now, more than ever, it seems to me that, in order to encourage people's virtuous behaviour, which is so crucial at the present time, communication must do everything is possible to promote an adequate perception of risk.

This is particularly true when it comes to transmitting statistical and probabilistic data to an audience of non-experts, inevitably conditioning their perception of risk. Data are all available, but subjects are able to understand them in the specific meanings proper to a specialized language, only if they are adequately transmitted. Then, the particular interpretation of the data, required for a correct understanding, needs a "particularized," marked formulation. Continuing to provide by media numbers on new infections, e.g. in absolute numbers or percentages, only rarely clarifying which base line is referred to and how this changes with the increase in the number of tests carried out and the type of tested population (random population vs. physicians and nurses vs. elderly people in community), does not allow to have an effective perception of the real meaning of the data. The vague trace that remains in leaves only an indefinite sense of improvement or worse of the situation. Good intentions and scientificity are therefore necessary, but not sufficient, conditions for the message that the speaker wants to convey to the listener to be truly informative and to have a persuasive potential.

Specialized languages, such as logical or statistical, presuppose an exclusive and unambiguous interpretation of the content in accordance with a shared code; the common language must instead be interpreted through inferential processes, in light of the attribution of intentions among the interlocutors. We explored confusion in inversed conditional probabilities, the low awareness of the importance to define the base line in understanding percentages and the right denominators for frequency etc. (Barbey and Sloman 2007; Macchi 1995, 2000; Macchi and Bagassi 2007), and how we formulate probabilistic judgments about low probability events (Koehler and Macchi 2004; Macchi et al. 1999). And we find again these phenomena in the difficulty in representing the trend of, for instance, Covid-19 contagion, based on probability of contagion and mortality. In particular, in the daily update of data on the spread of contagion, it is difficult to distinguish the rate of contagion from the absolute number of infected people compared to the maximum "peak" of infections (for "the science of science communication" see Baddeley 1978; Fischhoff 2013; Fischhoff and Scheufele 2014).

There is a gap between scientific, specialistic language and natural language: Logic and natural language, for instance, share a common aim of transmitting meaning efficaciously or, in other words, of communicating, of expressing thought. However, this objective is achieved by these two language forms in opposite ways: logic achieves a univocal communication, through simplification, eliminating any meanings that might interfere with the univocal meaning to be communicated, whereas natural lan-guage exploits the expressive richness of words, by relying on the pertinence of the mean-ing to the context. There is no hierarchical order between natural language and logical language in the sense that the former is inferior or subordinate to the latter. The two simply reflect different needs: in the first case, the need to ensure the efficacy of the com-munication; in the second, the need to guarantee the rigor of the inferential pro-cess. Logical discourse derives from common (or natural) 
discourse by a process of differentiation that, in a certain sense, establishes it as a specialist discourse. The two languages are differentiated (and in this sense different), but not in the sense of being completely separate or lacking a common basis. Two constants in the history of modern logic are the tendency toward the elimination of psychological aspects and the simplification of the ambiguity of language (a justified simplification, but one that is often anti-economic from a communicative point of view).

In general, then, when we communicate scientific terms or data we should reintroduce the psychological aspects which characterize communication.

In official communications, the intention is high, the data comes from reliable and scientifically recognised sources, and even if the explanation of the data is exhaustive, the message may still not be considered persuasive. It is not enough to offer objective information to have a subjective impact. A scientific communication that aims not only to divulge information, but also to persuade listeners, must take on the so-called "cognitive complex" (Mosconi 1978): The supporting structure of persuasive speech must rest on one or more elements accepted by the listener. The cognitive complex of a person is not a coherent and organic system. It is made up of partial systems, in turn internally more or less coherent and organic, tending to establish relations of compatibility or integration between them (with the possible consequence of modifications or rejection of parts of the complex). The cognitive complex, a product of culture and personal experience, always remains composed of heterogeneous elements or parts and characterised by significantly different levels of organisation of the individual parts. If the cognitive complex were a coherent and organic system, most of the persuasive processes that take place would be impossible. It is the heterogeneity of the material that makes up the cognitive complex, the various levels of organisation and integration between its parts, which make it possible to construct or activate a different subsystem. Through the introduction of a different way of reading, a different reference scheme, which allows new elements, information and criteria extraneous to the previous system to intervene, to establish new and different links between the elements, to change their value, weight and so on.

A part from numbers, we are overwhelmed by suggestions, warnings, tips: It seems obvious that suggestions or nudging are certainly not enough to influence the behaviour of the subjects. It is not sufficient to give an indication, to set up the architecture of the choice for a certain behaviour to take place. The acceptance of the suggestion, the effectiveness of the nudging implies the congruity with the system that receives it: the "way of reasoning", and its implicit layer has to be taken into account. The phenomenon of nudging can be considered as a prototype of approach to overcome risky behaviours, which takes into account the cognitive characteristics of the human system. This strategy acts on different levels, using implicit factors, bypassing defensive attitudes and exploiting adaptive inferential processes, without overloading the cognitive system. The framing effect, for instance, has been widely used to encourage or promote socially desirable or less risky behaviour, including reducing energy consumption, promoting flu vaccine, healthier nutrition, and so on. Framing can be considered as a prototype example of the use of "nudge" (Thaler and Sunstein 2008) in decision making. 
But from a communicative point of view, nudge, as well as any other type of intervention, is not a general 'recipe': The choice of a certain frame by the speaker conveys the adopted point of view, implicitly providing information that goes beyond its literal content and consequently influencing the message received by the listener, in terms of trust and perceived intentions of the source. According to this perspective, what deserves a particular attention is the interpretative dimension elicited by the specific interlocutors and contexts involved. The default option adopted in nudge intervention for instance, or the adopted frame in communication implicitly transmits perspectives and intentions of the choice architects. The right combination of the source, the adopted message and the decisional setting could improve the efficacy of the public policies. Tacit knowledge, implicit presuppositions and implications are the necessary background of any kind of communication, and their consideration influences the degree of efficacy of a discourse, communication, nudge intervention (Bagassi and Macchi 2016). According to this perspective, I would like to consider a nudge or a debiasing policy as communicative acts, that deserve a particular focus on the interpretative dimension elicited by the specific interlocutors and contexts involved.

In the end, every decision-making situation is like a speech, a conversation between a speaker and a listener conceived as a cooperative venture: the context, the characteristics of the speaker and the listener, common knowledge and the intention of the discourse, everything contributes to determining the interpretation of the message by the listener, through sophisticated, but at the same time immediate and adaptive, inferential processes of meaning attribution. Actually, we are characterized by a specialized type of intelligence, an interactional intelligence, with biological adaptive basis for interactive skills, coordination and communication (Levinson 1995, 2013; Mercier and Sperber 2011; Sperber and Wilson 1986/1995; Tomasello 2009).

In order to understand how and what to communicate, it is also necessary to understand the imaginary representation related to the infection in the present situation, and how this is evolving over time. It can be ineffective to insist on the moral function of containing contagion and protecting others (moral messaging), while we adopt protecting behaviours for utilitarian reason. Furthermore, the effectiveness of different messages may depend on who communicates them to whom (Macchi 2019). If we do not consider implict, unconscious layers of thinking we will not be able to predict and prevent behaviors that can risk to vanish the essential indications of use of masks and social distancing. The adoption, above all, of physical devices that we wear, such as masks and gloves, unconsciously 'absolve' us from behaviours that, if implemented, risk to invalidate the effectiveness of the devices themselves. For instance, the ritual of disinfecting hands with gloves before entering the supermarket risks even becoming a "purifier ritual", after which people put the shopping list back at the center of their attentional focus, forgetting social distancing. The social and quasi-magic thought expressed in our behaviour reveals our being defenseless with respect to uncertainty, because if we are not aware of the actual function of the devices and the purposes that guide us to use them, as well as our social automatisms, we risk getting rid of the thought, having fulfilled the conditions, the "price" to pay in order to pursue our own contingent purposes. This 
emerges in our daily behaviour and goes far beyond our intentions of which we are aware. Communications must also take charge of and address this dimension, which goes far beyond the good intentions that we all have.

\section{References}

Baddeley AD (1978) Applied cognitive and cognitive applied research. In: Nilsson LG (ed) Perspectives on memory research. Lawrence Erlbaum, Hillsdale

Bagassi M, Macchi L (2016) The Fundamental interpretative function and the emergence of unconscious analytic thought. In: Macchi L, Bagassi M, Viale R (eds) Cognitive unconscious and human rationality. MIT Press, Cambridge, pp 43-76

Barbey AK, Sloman SA (2007) Base-rate respect: from ecological rationality to dual processes. Behav Brain Sci 30(3):241-297

Fischhoff B (2013) The science of science communication. PNAS 110(3):14033-14039

Fischhoff B, Scheufele DA (2014) The Science of Science Communication II. PNAS 111(4):13583-13584

Koehler JJ, Macchi L (2004) Thinking about low-probability events—an exemplar-cuing theory. Psychol Sci 15(8):540-546

Levinson SC (1995) Interactional biases in human thinking. In: Goody E (ed) Social intelligence and interaction. Cambridge University Press, Cambridge

Macchi L (1995) Pragmatic aspects of the base-rate fallacy. Q J Exp Psychol A Hum Exp Psychol 48(1):188-207

Macchi L (2000) Partitive formulation of information in probabilistic problems: beyond heuristics and frequency format explanations. Organ Behav Hum Decis Process 82(2):217-236

Macchi L (2019).Nudge and communication: implicit layers of language, thought and decision making. In: XVI AISC annual conference 2019, Roma, December

Macchi L, Bagassi M (2007) The underinformative formulation of conditional probability. Behav Brain Sci 30(3):274-275

Macchi L, Osherson D, Krantz EH (1999) A note on superadditive probability judgment. Psychol Rev 106(1):210-214

Mercier H, Sperber D (2011) Why do humans reason? Arguments for an argumentative theory. Behav Brain Sci 34:57-111

Mosconi G (1978) Il pensiero discorsivo. Il Mulino, Bologna

Sperber D, Wilson D (1995) Relevance: communication and cognition. Blackwell, Oxford (Original work published 1986.)

Thaler RH, Sunstein CR (2008) Nudge: improving decisions about health, wealth and happiness. Yale University Press, New Haven

Tomasello M (2009) Why we cooperate. MIT Press, Cambridge

Publisher's Note Springer Nature remains neutral with regard to jurisdictional claims in published maps and institutional affiliations. 